\title{
Analisa Penggunaan Regenerative Brake pada Mobil Multiguna Pedesaan Bertenaga Listrik
}

\author{
Pradipta Bintang Perdana dan I Nyoman Sutantra \\ Departemen Teknik Mesin, Fakultas Teknologi Industri, Institut Teknologi Sepuluh Nopember (ITS) \\ e-mail: tantra@me.its.ac.id
}

\begin{abstract}
Abstrak-Keterbatasan energi merupakan permasalahan yang akan berpengaruh besar kedepannya. Peningkatan jumlah penduduk menambah parah permasalahan tersebut. Kendaraan listrik merupakan salah satu solusi yang menjawab permasalahan tersebut. Penggunaan kendaraan listrik didukung oleh sistem pengereman yang mampu menyerap energi yang terbuang dari proses pengereman yaitu regenerative brake. Dalam mendesain pengereman regeneratif yang baik bagi kendaraan perlu didesain porsi pengereman terlebih dahulu. Porsi pengereman ini meliputi porsi pengereman mekanik pada roda depan dan belakang serta pengereman regeneratif. Porsi pengereman yang aman mengikuti batas maksimal pengereman ideal serta batas minimal standar pengereman ECE. Setelah didapat porsi yang aman serta sesuai dengan kondisi aktual, selanjutnya mencari energi bangkitan dari sistem regenerative brake dengan mensimulasikan blok model pengereman kendaraan dengan bantuan software. Dari simulasi tersebut bisa didapatkan energi yang diserap serta energi pengereman yang tersedia. Dengan membandingkan energi yang diserap dengan energi pengereman yang tersedia didapat efisiensi sistem regenerative brake. Sistem regenerative brake mampu menyerap 1,738 $\mathrm{kWh}$ dengan efisiensi $51,74 \%$ pada porsi pengereman regeneratif 0,1247 serta pengereman mekanis depan 0,6758 dan belakang tidak ada pada koefisien gesekjalan 0,8 .
\end{abstract}

Kata Kunci-regenerative brake, energi bangkitan, simulasi.

\section{PENDAHULUAN}

$\mathrm{P}$ ERTUMBUHAN jumlah penduduk semakin hari semakin mengkhawatirkan. Menurut data BKKBN laju pertumbuhan penduduk di Indonesia mencapai 1,49 persen at au sekitar empat juta pertahun [1]. Pertumbuhan yang sangat besar tersebut menyebabkan ledakan penduduk. Salah satu akibatnya, kebutuhan akan bahan bakar sebagai sumber energi utama kendaraan juga naik. Padahal ketersediaan bahan bakar masih terbatas. Selain itu penggunaan bahan bakar fosil juga dapat menghasilkan emisi yang berbahaya untuk lingkungan

Salah satu solusi untuk mengurangi konsumsi bahan bakar fosil ditengah naiknya kebutuhan akan alat transportasi adalah dengan pemanfaatan sistem regenerative brake pada kendaraan. Regenerative brake merupakan suatu sistem pengereman elektrik yang memperlambat kendaraan sekaligus menyerap energi kinetik dari proses pengereman tersebut. Agar sistem regenerative brake dapat bekerja dengan baik tanpa mengurangi kinerja pengereman maka diperlukan porsi pengereman antara regenerative brake dan sistem rem mekanik. Pada umumnya, mobil listrik yang sudah diproduksi massal menggunakan regenerative brake untuk meningkatkan efektivitas energi yang digunakan.

Sistem regeneratie brake sangat cocok digunakan pada mobil multiguna pedesaan. Mobil multiguna pedesaan merupakan mobil yang dapat melakukan empat fungsi sekaligus yakni mobil toko, mobil penumpang, mobil pengangkut barang, serta mobil produksi. Dengan adanya empat fungsitersebut pastinya memerlukan energi yang tidak sedikit. Sistem regenerative brake yang digunakan dapat mengembalikan energi yang terbuang dan digunakan untuk meningkatkan jarak tempuh kendaraan.

Kendaraan listrik dibagi menjadi 2 model yaitu kendaraan listrik menggunakan motor tak langsung yaitu hanya memakai satu motor dan yang kedua adalah kendaraan listrik dengan motor langsung yaitu menggunakan 2 atau 4 motor listrik yang langsung menempel pada roda penggerak. Kendaraan listrik dengan motor tak langsung konsepnya sama dengan kendaraan menggunakan mesin biasa. Transmisi yang digunakan sama dengan kendaraan biasa. Motor listrik pada kendaraan ini menggantikan fungsi dari mesin pada kendaraan biasa, jadi energi kinetik dari motor listrik ditransmisikan oleh sistem penyalur daya menjadi gaya dorong pada roda penggerak [2].

Jumlah energi yang dapat dibangkitkan pada saat proses pengereman tergantung dari besarnya regenerative braking yang bekerja pada kendaraan. Untuk mendapatkan jumlah energi pengereman yang maksimum, maka harus dilakukan analisa dan perhitungan awal terhadap distribusi gaya pengereman yang terjadi pada roda bagian depan dan roda bagian belakang. Gaya pengereman di kedua roda pada kendaraan memiliki suatu rasio tetap yang dibatasi oleh nilai koefisien gesek dari lintasan yang dilalui dan jumlahnya harus seimbang dengan beban normal pada roda kendaraan, sehingga roda kendaraan bagian depan dan bagian belakang pada kendaraan tersebut mendapatkan gaya peng ereman maksimum secara bersamaan [3].

\section{URAIAN PENELITIAN}

Metodologipenelitian ini dilakukan dalam beberapa tahapan. Tahapan pertama adalah melakukan studi literatur tentang regenerative brake pada kendaraan. Pengumpulan materi dapat dilakukan dari berbagai sumber antara lain penelitian terdahulu, text book, jurnal penelitian, hand book, dan penelusuran di

Tabel 1.
Spesifikasi Mobil Multiguna Pedesaan

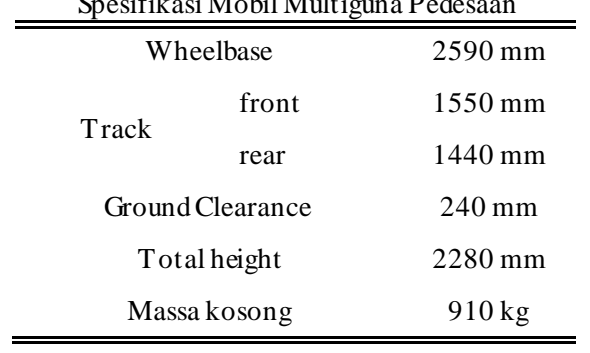




\begin{tabular}{cc}
\hline \hline Maksimal muatan & $590 \mathrm{~kg}$ \\
Jarak roda depan ke CG & $1090 \mathrm{~mm}$ \\
Tinggi CG ke permukaan tanah & $860 \mathrm{~mm}$ \\
massa jenis udara & $1,2 \mathrm{~kg} / \mathrm{m}^{3}$ \\
koefisien drag kendaraan & 0,4 \\
luas frontal kendaraan & $2,9088 \mathrm{~mm}^{2}$ \\
koefisien rolling & 0,01 \\
koefisien adhesi jalan & 0,9 \\
Diameter roda & $594,2 \mathrm{~mm}$ \\
\hline \hline
\end{tabular}

WLTC Class 1

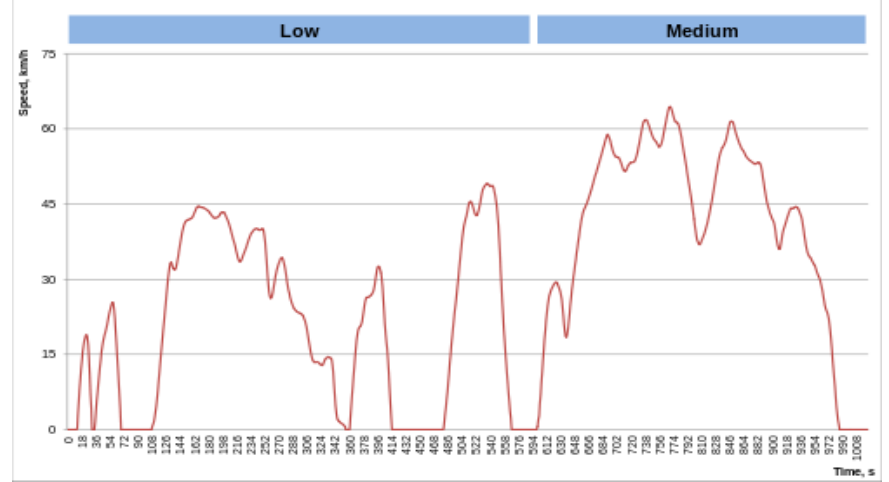

Gambar 1.Grafik Driving Cycle WLTP Class 1.

internet. Data-data yang digunakan antaral lain berupa spesifikasi kendaraan serta driving cycle.

Tahapan selanjutnya yaitu menentukan konsep masalah. Materi yang didapatkan dari studi literatur selanjutnya dirumuskan menjadi poin-poin permasalahan. Hasil dari tahapan ini berupa perumusan masalah yang terdapat pada bagian pendahuluan

Tahapan ketiga adalah mengumpulkan data-data yang mendukung penelitian. Data yang diperlukan berkaitan dengan mobil multiguna pedesaan antara lain dimensi kendaraan serta data yang mempengaruhi gaya yang bekerja pada kendaraan. Selain itu juga diperlukan data berupa drive cycle untuk mengetahui perilaku kendaraan saat berjalan.

Tahapan keempat menentukan model pengereman kendaraan. Pada tahap ini dilakukan pemodelan pengereman kendaraan yang hasilnya berupa kurva distribusi pengereman. Kurva yang didesain tidak boleh melebihi kurva pengereman ideal yang kurvanya bisa didapatkan dengan variasi nilai a/g serta $\mathrm{Fb}_{f} / \mathrm{W}$ dari 0,1 hingga 0,8 pada persamaan 1 .

$$
\frac{F b_{r}}{W}=\frac{\left(L_{f}-\frac{a}{g} \cdot h\right)}{\left(L_{r}+\frac{a}{g} \cdot h\right)} \times \frac{F b_{f}}{W}
$$

Kurva pengereman juga tidak boleh kurang dari standar minimal pengereman ECE dengan variasi nilai a/g dari 0,1 hingga 0,8 pada persamaan :

$$
\frac{F b_{f}}{W}=\frac{\mu}{L}\left(L_{r}+(0.1+0.85(\mu-0.2) h)\right)
$$

$\frac{F b_{r}}{W} \geq(0.1+0.85(\mu-0.2))-\frac{F b_{f}}{W}$

Tahap kelima adalah menganalisa porsi pengereman antara rem mekanik dan rem elektrik dari kurva distribusi pengereman dari tahap sebelumnya. Porsi pengereman juga divariasikan dengan koefisien gesekjalan sesuai dengan jalan pada pedesaan pada umumnya. Setelah didapat porsi pengereman yang cocok, selanjutnya mencari gaya yang diperlukan untuk proses pengereman kendaraan.

Tahap keenam adalah menganalisa seberapa besar potensi daya yang dapat dibangkitkan oleh sistem regenerative brake dan disimpan pada baterai. Proses analisa menggunakan software dengan memodelkan sistem pengereman. Model sistem pengereman mencakup blok gaya pengereman.

Susunan blok gaya mengikuti persamaan :

$F_{b}=F_{a}-F_{d}-F_{r}$

Dimana $\mathrm{F}_{\mathrm{a}}$ merupakan gaya inersia dengan persamaan :

$F_{a}=m \cdot a$

$\mathrm{F}_{\mathrm{d}}$ merupakan gaya hambat drag dengan persamaan :

$F_{d}=\frac{1}{2} \cdot \rho \cdot C d \cdot A f \cdot v^{2}$

Dan Fr adalah gaya hambat rolling dengan persamaan :

$F_{r}=m \cdot g \cdot C_{f}$

Selain gaya pengereman terdapat blok model untuk mengkonversi gay a pengereman menjadi energi pengereman mengikuti persamaan :

$T_{\text {bmotor }}=\frac{F_{b} \times r}{I_{t} \times I_{g} \times \eta}$
$\omega_{\text {motor }}=\frac{v \times I_{t} \times I_{g}}{\pi \times r}$
$P_{b}=T_{\text {bmotor }} \times \omega_{\text {motor }}$

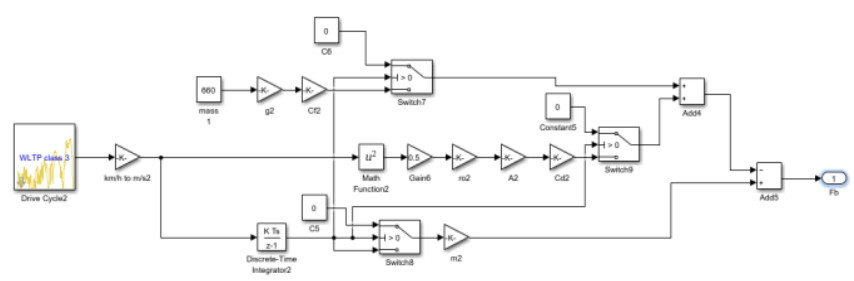

Gambar 2. Blok Gaya pengereman.

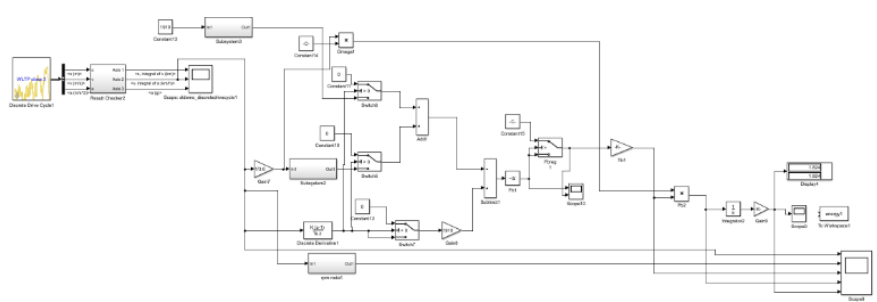

Gambar 3.Blok Gabungan.

Tahap terakhir adalah mencari efisiensi sistem regenerative brake dalam membangkitkan energi kinetik yang terbuang dari proses pengereman. Efisiensi sistem regenerative brake didapat dari perbandingan hasil simulasi software energi regenerative 
brake dengan energi pengereman total (rem mekanik dan rem regeneratif).

\section{HASIL DAN ANALISA}

\section{A. Porsi Pengereman Kendaraan}

Kurva porsi pengereman menunjukkan kurva pengereman ideal dan kurva standar pengereman ECE sebagai batas maksimal dan minimal untuk porsi pengereman yang akan digunakan pada kendaraan sesuaidengan gambar 3.

Kurva pengereman ideal didapat dari persamaan 1 dengan porsi $\mathrm{Fb}_{\mathrm{r}} / \mathrm{W}$ 0,0633 pada saat nilai a/g 0,1 dan $\mathrm{Fb}_{\mathrm{f}} / \mathrm{W}$ 0,1 hingga porsipaling besar 0,1709 pada nilai a/g dan $\mathrm{Fb}_{f} / \mathrm{W}$ 0,5 dan 0,125 pada nilai a/g 0,9 dan $\mathrm{Fb}_{f} / \mathrm{W}$ 0,9. Porsi pengereman standarECE dari kendaraan didapat sebesar 0,0024 pada a/g 0,4, sebesar 0,0064 pada a/g 0,5 dan 0,0048 pada a/g 0,6. Selain itu nilai $\mathrm{Fb}_{f} / \mathrm{W}$ pada variasi nilai a/g lain dibawah 0 sehingga dalam proses mencari porsi pengereman kendaraan bisa diabaikan. Kurva yan didapat pada grafik dengan warna merah antara kurva pengereman ideal dan kurva pengereman stadarECE.

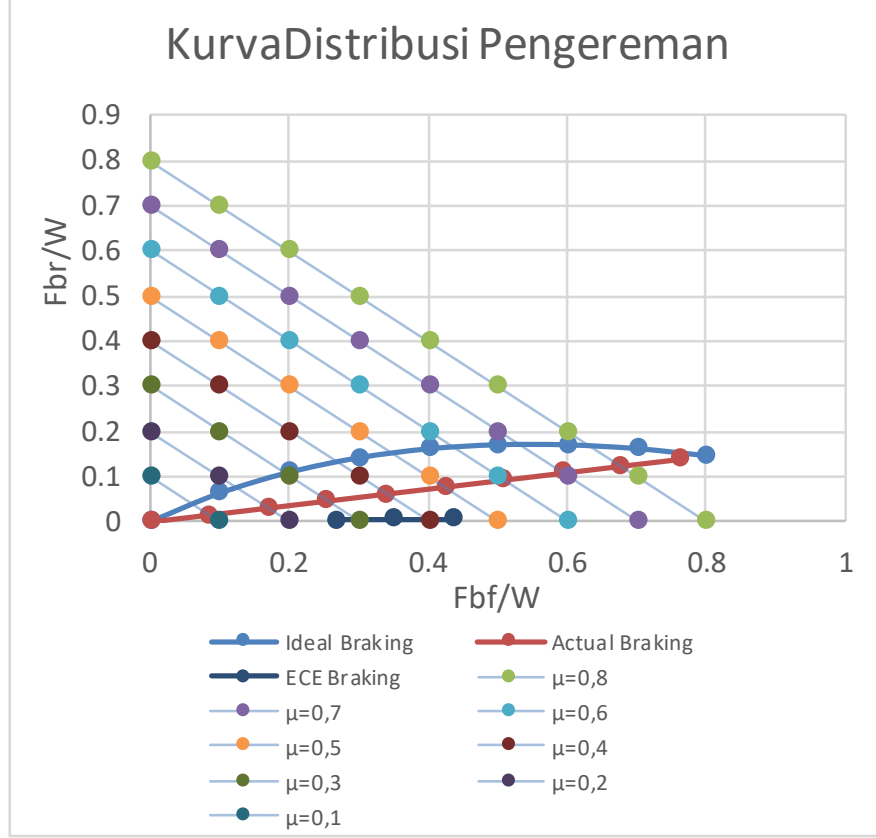

Gambar 4. Kurva distribusi pengereman mobil multiguna pedesaan bertenaga listrik.

Sistem regenerative brake dirancang pada roda bagian depan dan dilakukan pada awal pengereman. Porsi pengereman regenerative brake didapat dari kemampuan motor-generator yang digunakan dengan spesifikasi torsi motor-generator 390 Nm. Sehigga kemampuan maksimal pengereman oleh motor dapat diketahui dengan persamaan 8 sebesar 9775,97 N. Gaya itu dapat mencapai porsi pengereman maksimal 0,5217. Akan tetapi porsi pengereman regenerative brake yang digunakan pada kondisi tertentu tidak bisa mencapai nilai 0,5217 agar menjaga proses pengereman kendaraan tetap aman.

Sistem regenerative brake dapat diaplikasikan baik pada roda depan maupun roda belakang. Adanya sistem regenerative brake ini tentunya mempengaruhi porsi pengereman mekanis yang digunakan dapat lebih kecil bahkan ditiadakan tergantung besar porsinya [4]. Porsi pengereman kendaraan saat sistem regenerative brake terhubung dengan roda depan pada kondisi koefisien gesek jalan 0,5-0,8 tersaji pada tabel 2 .

Dari porsi pengereman sesuai tabel 2 dapat diketahui porsi rem mekanis pada koefisien gesek jalan 0,5 dan 0,6 tidak ada, pengereman pada roda depan sepenuhnya dengan pengereman regeneratif. Sementara pada koefisien gesek jalan 0,7 dan 0,8 porsi pengereman regeneratif maksimal ditambah porsi pengereman mekanis. Untuk porsi pengereman roda belakang sesuai dengan porsi yang telah ditentukan sebelumnya.

Nilai gaya pengereman yang dibutuhkan pada masingmasing roda depan dan roda belakang serta regenerative brake dengan mengalikan porsi pengereman dengan berat mobil sehingga didapat nilai gaya pengereman.

Diketahui mobil multiguna pedesaan yang digunakan merupakan mobil dengan penggerak roda belakang sehingga meskipun potensienergi pengereman yang dapat dibangkitkan besar, akan tetapi perlu beberapa modifikasi untuk menggunakan regenerative brake pada roda depan. Porsi pengereman pada saat sistem regenerative brake terdapat pada roda belakang tersaji pada tabel 4 .

Tabel 2.

Porsi Pengereman Kendaraan Regeneratif Roda Depan

\begin{tabular}{llrl}
\hline \hline$\mu$ & Fb reg/W & Fbf/W & Fbr/W \\
\hline 0,5 & 0,422394 & 0 & 0,077606 \\
0,6 & 0,506873 & 0 & 0,093127 \\
0,7 & 0,521744 & 0,069607 & 0,108649 \\
0,8 & 0,521744 & 0,154086 & 0,12417 \\
\hline \hline
\end{tabular}

Tabel 3.

Gaya Pengereman Kendaraan Regeneratif Roda Depan

\begin{tabular}{lrrl}
\hline \hline$\mu$ & Fb reg $(\mathrm{N})$ & Fbf $(\mathrm{N})$ & Fbr $(\mathrm{N})$ \\
\hline 0,5 & 7914,435 & 0 & 1454,115 \\
0,6 & 9497,322 & 0 & 1744,938 \\
0,7 & 9775,97 & 1304,239 & 2035,761 \\
0,8 & 9775,97 & 2887,126 & 2326,584 \\
\hline \hline
\end{tabular}

Tabel 4.

Porsi Pengereman Kendaraan Regeneratif Roda Belakang

\begin{tabular}{cccr}
\hline$\mu$ & Fb reg/W & Fbf/W & Fbr/W \\
\hline 0,5 & 0,077606 & 0,422394 & 0 \\
0,6 & 0,093127 & 0,506873 & 0 \\
0,7 & 0,108649 & 0,591351 & 0 \\
0,8 & 0,12417 & 0,67583 & 0 \\
\hline \hline
\end{tabular}

Tabel 5 .

Gaya Pengereman Kendaraan Regeneratif Roda Belakang

\begin{tabular}{lllr}
\hline \hline$\mu$ & Fb reg/W & Fbf/W & Fbr/W \\
\hline 0,5 & 1454,115 & 7914,435 & 0 \\
0,6 & 1744,938 & 9497,322 & 0 \\
0,7 & 2035,761 & 11080,21 & 0 \\
0,8 & 2326,584 & 12663,1 & 0 \\
\hline \hline
\end{tabular}


Porsi regenerative braking pada roda belakang lebih kecil daripada porsi regenerative braking pada roda depan dikarenakan porsi pengereman yang didesain lebih besar pada roda depan dibandingkan pada roda belakang. Akibatnya pada porsi pengereman roda belakang tidak diperlukan pengereman mekanis karena porsi pengereman roda belakang sudah dicukupi oleh regenerative brake.

\section{B. Analisa Energi Bangkitan Maksimal Kendaraan}

Energi bangkitan maksimal yang mampu diserap kendaraan didapat dari simulasi pada software sesuai blok-blok model yang telah didesain. Energi bangkitan yang dapat diserap sistem regenerative brake dapat dilihat pada gambar 4. Porsi yang digunakan sesuai dengan porsi regenerative brake pada roda belakang dengan koefisien gesek jalan 0,8 sebesar 0,1241.

Sesuai grafik diatas, energi bangkitan total yang mampu diserap dari hasil simulasi sebesar 1,824 $\mathrm{kWh}$ pada satu siklus driving cycle WLTP kelas 1. Selanjutnya energi yang dapat disimpan pada baterai harus melewati generator untuk diubah menjadi energi listrik. Generator yang digunakan memiliki efisiensi sebesar $95 \%$ sehingga energi yang mampu diserap dan disimpan pada baterai sebesar $1,7328 \mathrm{kWh}$.

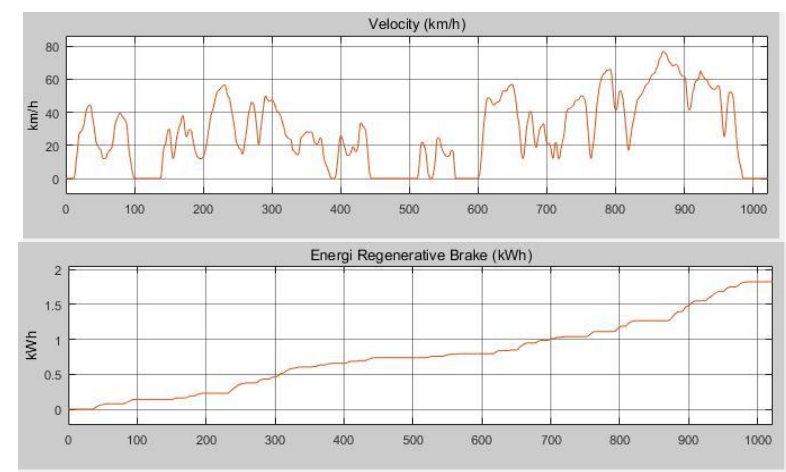

Gambar 4. Energi Bangkitan Regenerative Brake.

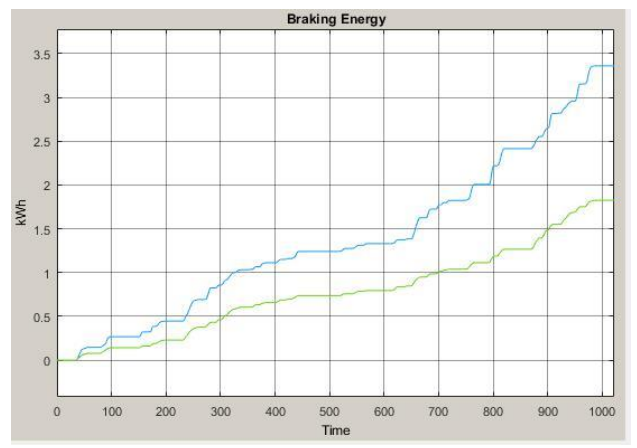

Gambar 5. Energi Pengereman dan Energi Bangkitan Regenerative Brake.

\section{Mencari Efisiensi Sistem Regenerative Brake}

Mencari nilai efisiensi sistem regenerative brake terlebih dulu mencari energi pengereman total yang digunakan dalam proses pengereman kendaraan. Energi pengereman total dapat diketahui dari hasil simulasi dengan blok model regenerative brake dengan porsi keseluruhan pengereman. Hasil simulasi didapat grafik pada gambar 5 .

Pada gambar diatas, grafik biru menunjukkan energi pengereman keseluruhan yang digunakan untuk perlambatan kendaraan sementara grafik hijau merupakan energi regenerative brake yang mampu diserap sistem sesuai porsi regenerative brake yang telah didesain. Total energi pengereman yang tersedia sebesar $3,359 \mathrm{kWh}$ sementara energi yang diserap dari perhitungan sebelumnya sebes ar 1,7328 kWh. Didapat efisiensi sistem regenerative brake sebesar $51,74 \%$

\section{KESIMPULAN}

Pada tugas akhir ini, kesimpulan dari analisa sistem regenerative brake pada mobil multiguna pedesaan bertenaga listrik adalah:

1. Porsi regenerative braking pada mobil multiguna pedesaan bertenaga listrik bervariasi sesuai dengan koefisien gesek jalan antara 0,0776 pada koefisien gesek jalan 0,5 hingga 0,1241 pada koefisien gesek jalan 0,8. Porsi pengereman mekanis pada roda depan juga bervariasi mengikuti koefisien gesek jalan. Sementara porsi pengereman mekanis pada roda belakang tidak diperlukan.

Tabel 6.

Porsi Pengereman Kendaraan

\begin{tabular}{lllr}
\hline \hline$\mu$ & Fb reg/W & Fbf/W & Fbr/W \\
\hline 0,5 & 0,077606 & 0,422394 & 0 \\
0,6 & 0,093127 & 0,506873 & 0 \\
0,7 & 0,108649 & 0,591351 & 0 \\
0,8 & 0,12417 & 0,67583 & 0 \\
\hline \hline
\end{tabular}

Tabel 7.

Gaya Pengereman Kendaraan

\begin{tabular}{lllr}
\hline \hline$\mu$ & Fb reg/W & Fbf/W & Fbr/W \\
\hline 0,5 & 1454,115 & 7914,435 & 0 \\
0,6 & 1744,938 & 9497,322 & 0 \\
0,7 & 2035,761 & 11080,21 & 0 \\
0,8 & 2326,584 & 12663,1 & 0 \\
\hline \hline
\end{tabular}

2. Energi bangkitan yang mampu dibangkitkan sistem regenerative brake dan disimpan pada baterai dalam satu siklus driving cycle WLTP kelas 1 adalah sebesar 1,738 kWh pada koefisien gesek jalan 0,8 .

3. Efisiensi sistem regenerative brake yang dirancang pada mobil mutlguna pedesaan bertenaga listrik ini sebesar $51,74 \%$

\section{DAFTAR PUSTAKA}

BKKBN, "Laju Pertumbuhan Penduduk Empat Juta per Tahun," 2016. [Online]. Available: http://www.bkkbn.go.id/detail post/lajupertumbuhan-penduduk-4-jut a-per-tahun.

[2] S. . Nyoman, Teknologi Otomotif Hybrid, Institut Teknologi Sepuluh Nopember. Guna Widya, 2015.

[3] dan B. S. Sutantra, I Nyoman, Teknologi Otomotif, Edisi Kedua. Surabaya: Guna Widya, 2010.

[4] G. Wijaya, "Analisa Gaya Pengereman dan Energi yang Dibangkitkan dengan Porsi Regenerative Brake,” Surabaya, 2014. 